\title{
DOSSIÊ
}

FILE 



\section{DISCURSOS EPISTEMOLÓGICOS DE AFETIVIDADE COMO PRINCÍPIOS DE RACIONALIDADE PARA A EDUCAÇÃO CIENTÍFICA E MATEMÁTICA}

Rogério Gonçalves de Sousa*

Sandra Nazaré Dias Bastos**

RESUMO: Este ensaio tem como objetivo a compreensão e o estudo do papel da afetividade no processo de cognição, sob uma perspectiva voltada para valorização de aspectos indissociáveis do sujeito epistêmico, admitindo que este se constrói e constrói conhecimento em diversos domínios de raciocínio, inclusive emocionais. Para subsidiar a discussão no âmbito da Educação Científica e Matemática, reunimos relatos de docentes nos quais fica evidente que a afetividade influenciou o processo de ensino e aprendizagem. Partindo das narrativas e de diversas contribuições teóricas, buscamos evidenciar discursos epistemológicos e configurá-los como princípios de racionalidade para a Educação Científica e Matemática, sustentando como tese principal a imbricação da razão com a afetividade no caminho do conhecer.

Palavras-chave: Afetividade; Epistemologia; Educação Científica e Matemática.

\section{EPISTEMOLOGICAL DISCOURSES OF AFFECTION AS PRINCIPLES OF RATIONALITY FOR SCIENCE AND MATHEMATICS EDUCATION}

ABSTRACT: This essay aims to analyze and study the role of affection in cognitive processes from a perspective focused on appreciation of inseparable aspects of the epistemic subject, acknowledging that he develops himself and develops knowledge in various reasoning levels, including emotional ones. To support the discussion in Science and Mathematics Education, we gathered teacher reports that show that affection influenced both teaching and learning processes. From narratives and several theoretical contributions, we aimed to emphasize epistemological discourses and establish them as principles of rationality for Science and Mathematics Education, supporting the thesis of the overlap between reason and affection in the path of knowing.

Keywords: Affection; Epistemology; Science and Mathematics Education. 


\section{INTRODUĈ̣̃O}

No âmbito de nossa formação doutoral em Educação Científica e Matemática, temos participado de discussões que objetivam, dentre outras metas, compreender e estudar o papel da afetividade no processo de cognição, sob uma perspectiva que valorize o sujeito epistêmico em sua totalidade. Aqui sintetizamos as ideias que formulamos na interação com professores de Ciências e Matemática ${ }^{1}$, particularmente a análise de relatos escritos por esses docentes ao nos contarem situações de ensino nas quais ficou evidente que elementos afetivos constituíram o processo educativo dos envolvidos. Com base nas narrativas e em contribuições teóricas, buscamos formular para a Educação Científica e Matemática princípios de racionalidade compatíveis com essa 'nova' visão sistêmica do ser que aprende. Consideramos a discussão relevante para a área, sobretudo diante do olhar de complexidade e compromisso que a dimensão afetiva exige dos responsáveis pela educação em geral.

\section{A RAZÃO E A PAIXÃO SÃO 0 LEME DA ALMA NAVEGANTE}

Ao interagir com a realidade, participando de práticas sociais e processos de aquisição de conhecimento, o ser humano desenvolve suas potencialidades em múltiplas dimensões. Wallon (1975) postula que a razão e a afetividade são os principais domínios funcionais de nossas relações. Sob esse ângulo, o homem constrói seus saberes na conjunção de ambos os domínios e qualquer análise cindida entre razão e emoção resulta numa visão distorcida da própria natureza humana.

Apesar de hoje plausível, a perspectiva na qual pensamento e sentimento se imbricam no processo cognitivo não constituiu o paradigma da modernidade tardia, sendo uma concepção oriunda de recentes discursos epistemológicos que contrapõem a simplificação da subjetividade humana. Sobre o assunto, Custódio (2007, p.17) nos diz que "a oposição entre afeto e cognição talvez seja uma das crenças mais fortemente inculcadas pela nossa cultura ocidental”. Em nossa época prevalece o discurso hegemônico ocidental, qual seja, o de que a razão, considerada uma habilidade humana refinada, existe e se mantém separada da emoção para garantir a objetividade do conhecimento, um dos pilares do pensamento científico moderno.

Para alguns, o dualismo razão-emoção se justificou epistemologicamente pela necessidade de descrição sistemática dos fenômenos naturais e pela simplificação da óptica dos pressupostos teóricos com os quais a fenomenologia era examinada (ALMEIDA et al., 2009; SANTANA; ROAZZI; DIAS, 2006; RODRIGUES, 2001). Desse modo, a Ciência se configurou como atividade humana afastada da ambiguidade, da imprevisibilidade e da contradição. Autores como Neubern (2000) apontam que essa escolha marginalizou outras formas de interpretação das realidades, tais como a realidade de subjetividade, a espiritual, a de senso-comum, dentre outras.

Nos estudos da Psicologia, um dos efeitos desse discurso foi o tratamento 
distintivo das dimensões afetiva e racional no funcionamento do aparelho psicológico humano (ARANTES, 2003; OLIVEIRA, 1992). Para Neubern (2000), o retalhamento dos processos psicológicos resultou em tendências epistemológicas que reduziram os sentimentos a processos fisiológicos ou a construtos de linguagem e, assim, desconsideraram a interconexão natural da razão com a emoção.

Em contrapartida, as Neurociências têm demonstrado a complexidade dos processos mentais, afirmando que a atividade cerebral acontece de forma integrada, executada por neurônios de áreas distintas do córtex, dentre as quais participam as emoções (ANDRADE; PRADO, 2003; CAGNIN, 2008; PEDRO, 2007). Estudiosos como Damásio (2000, p.64) postulam que "a trama de nossa mente e de nosso comportamento é tecida ao redor de ciclos sucessivos de emoções seguidas por sentimentos", isto é, "numa polifonia contínua que sublinha e pontua pensamentos específicos em nossa mente e ações em nosso comportamento". Em suma, os processos de raciocínio são interativos e se constroem na interface razão-afetividade.

Essa compreensão parece não alcançar o âmbito da escola e seus constituintes, especialmente porque nele prevalecem dicotomias como afeto-cognição, sujeito-objeto, corpo-mente e se valoriza a dimensão intelectual do sujeito aprendente, segundo o reducionismo de que os sentimentos comprometem a eficácia e os objetivos da educação. Muitas vezes essa noção, que entendemos ser ingênua, implica em relações superficiais estabelecidas em sala de aula. Conforme argumentam Rodrigues e Garms (2007, p.32-33), não raro professores e estudantes são percebidos "destituídos de características como emoção e afeto, atribuindo-lhes apenas características necessárias ao ambiente escolar, como por exemplo, a cognição". Dessa forma, parte do processo de aprendizagem é ignorado por educadores e comunidade escolar.

Entendemos que na Educação Científica e Matemática esse cenário não é distinto. Em nossa experiência como professores, podemos observar a persistência da visão mecanicista do homem como máquina sustentada pelo paradigma que levou à disjunção razão-afetividade que hoje se mostra fenomenologicamente limitada. Vemos que 'não gosto de Matemática', 'não tenho prazer nas aulas de Biologia', 'Química é a matéria mais chata', 'Física é apavorante', são termos comuns nas aulas. Assertivas desse gênero têm nos levado a pensar que explicações científico-matemáticas 'isoladas' podem não alcançar o domínio afetivo de satisfação do aluno, tal qual experimentado quando compreende algo que lhe faça sentido, e que os aspectos afetivos são tão decisivos para a aprendizagem quanto a dimensão racional.

Essas inquietações têm levado a pesquisa em Educação em Ciências e Matemática a analisar o sujeito aprendiz em sua totalidade cognitiva (MONTEIRO; GASPAR, 2007; SANTOS, F., 2007; SENICIATO; CAVASSAN, 2008, ULLER, 2006). Dentre outros resultados, as investigações apontam que, quando não há motivação e interesse em aprender, o aluno não constrói vínculos afetivos com o conhecimento ensinado, deturpando ou até mesmo impedindo sua significação (CUSTÓDIO, 2007; PAULA; CUNHA, 2001; PIETROCOLA; PINHEIRO, 2000).

Contribuições desse porte nos ajudam a sustentar a tese de que a afeti- 
vidade é um aspecto indissociável do processo cognitivo. Entendemos que não é possível conceber estados afetivos sem elementos racionais, assim como comportamentos intelectivos sem a presença das emoções. Estudos epistemológicos clássicos como os de Wallon $(1975,1995)$ ajudaram a sustentar a ideia de que razão e emoção são domínios funcionais mutuamente inclusivos, imbricados num binômio que neste ensaio vamos chamar de binômio afeto-cognição.

Em termos epistemológicos compreendemos que a afetividade ${ }^{2}$ diz respeito a qualquer experiência emotiva vivenciada pelo sujeito em sua relação com o mundo, à forma como esse sujeito é afetado pelos acontecimentos da vida, o que não dispensa o domínio da razão, a singularidade e complexidade do aparelho epistêmico que o compõe, enfim, a aspectos indissociáveis do processo cognitivo. Motivados por tal entendimento, buscamos examinar relatos escritos de docentes de Ciências e Matemática para avaliarmos o papel da afetividade no processo educativo.

\section{HISTÓRIAS E ‘CAUSOS’ QUE SE REPETEM}

Nossa pesquisa possui cunho qualitativo e exploratório e nela utilizamos como técnica analítica a Análise de Conteúdo (BARDIN, 2010). Na ocasião do primeiro encontro no espaço de discussões que nos motivou a compor este artigo, convidamos os 11 (onze) participantes - doutorandos e docentes de Ciências/ Matemática - a relatarem por escrito episódios em sala de aula em que considerassem que a afetividade influenciou o processo de ensino e aprendizagem. Com efeito, pedimos que examinassem a proposição relate uma situação que você vivenciou em sala de aula na qual a afetividade teve papel fundamental na aprendizagem dos alunos.

Ao todo 7 (sete) docentes elaboraram relatos e desse montante selecionamos 4 (quatro) histórias ou 'causos' que, a nosso ver, atendem à finalidade da discussão aqui empreendida. $\mathrm{Na}$ análise de conteúdo das histórias, destacamos em negrito os termos que consideramos indicadores de afetividade. A partir dos textos, buscamos articular discursos epistemológicos defendidos pela pesquisa da área e formular princípios de racionalidade para a Educação Científica e Matemática.

Ressaltamos que realizamos alguns recortes e reescritas nas narrativas para podermos dialogar com os textos com os olhos 'cheios de teorias', sem que, contudo, isso resultasse em perda de sentido dos 'causos'. Portanto, preservamos quase que totalmente o conteúdo dos relatos, em especial os estratos em que os indícios de afetividade eram mais evidentes. Os nomes dos estudantes das estórias são fictícios. Feitos esses esclarecimentos, passamos à descrição dos textos.

(1) Havia um garoto, o Kevin, retido na série em que en lecionava Física. A coordenação pedagógica dizia que ele estava em 'situação de risco'. Percebi desde o início que o resto da turma não se aproximava dele. E ele também se isolava. Numa aula, propus que a tarefa fosse feita em pares. O Kevin não foi escolbido por ninguém. Ele ficou muito chateado. Pensei em recompor as duplas do meu jeito, mas antes que o fizesse, Kevin falou: "não tem problema não, 
professor. Eu faço sozinho'.

Observei o enorme esforço daquele garoto na atividade. Ele sabia a parte matemática, mas talvez a dificuldade fosse outra. No final da aula, chamei-o para sugerir algumas questões do livro e então ele me disse, de supetão: 'Eles não falam comigo porque repeti de ano, professor. E também porque já estive na malandragem'. Eu respirei fundo e disse com um sorriso: 'É, eu sei... Mas EU confio em você, pode contar e falar comigo'.

Claro que eu estava disposto a discutir a questão com a turma, porque acho que é minha função como educador. Na aula seguinte, eu disse: 'gente, não acredito que vocês não falam com 'fulano' ou 'cicrano' só porque ele é repetente. Poxa, cada um de vocês tem coisas boas pra compartilhar, basta querer. Cadê o respeito aqui em sala de aula? Olha, se eu tivesse um colega repetente, eu faria amizade com ele, porque com certeza ele tem muita coisa pra me ensinar'.

Lembro da fisionomia agradecida do Kevin e de outros alunos retidos. Depois disso, a situação mudou. Cada vez que en incentivava o Kevin, ele se mostrava mais interessado nas aulas. Criamos uma amizade e ele tinha um comportamento exemplar em sala, além de se mostrar disposto a superar suas dificuldades na matéria. Eu dizia 'você sabe Física', 'não desista', 'eu confio em você' e isso fez com que alguns colegas de turma fossem se aproximando dele. No meio do ano, Kevin havia se enturmado de verdade, ajudava os colegas e era uma liderança na turma.

(2) Escolbi Licenciatura em Biologia por que sempre amei Biologia, pensava em ser pesquisadora, docente de universidade, mas nunca em dar aulas na educação básica. Depois de formada, a tendência era de que eu fosse fazer Mestrado na área do bacharelado. Até eu cursar Prática de Ensino de Biologia. Fiquei encantada, apaixonada com a minha profissão, eu queria muito ser professora! Assim que me formei, no outro mês já estava trabalhando numa escola, para um ambiente conhecido e, ao mesmo tempo, desconhecido.

Um episódio que destaco daquela escola foi o caso da aluna Rebeca, da 1 a etapa da EJA. Todos os professores e os demais alunos consideravam-na um terror (atrevida, bagunceira, briguenta...). Na sala dos professores, ela era sempre o alvo de críticas ferozes, 'ela não tem jeito', 'tem que ser expulsa', 'é uma marginal'... Eu sempre me incomodei com tais comentários por que eu não via ninguém falar com ela. Decidi então conbecê-la melhor, e como eu ando a sala toda, conto "causos", me exponho, abro meu coração, trato os alunos com respeito, como gente, aos poucos eu consegui pequenos avanços.

Um dia, quando já conversávamos, fiquei sabendo de coisas muito tristes que aconteceram na vida de Rebeca. Ela sofreu abuso sexual aos 4 anos (morava no interior do estado), sua mãe a abandonou, passou a ser criada pela avó, depois a avó morreu, teve que mudar várias vezes de casa (tios, tias...) e aos 16 anos ganhava a vida fazendo programas (Rebeca era uma moça bonita). Ela se sentia inferior às outras pessoas, mas ela sempre dizia que queria estudar e ser alguém na vida..

(3) O Marcelo era um daqueles alunos tri-repetentes, na $5^{a}$ série, com idade bem acima dos demais. Não demonstrava interesse, mas também não apresentava mau comportamento, parecendo se sentir muito desconfortável com a situação. O que eu percebia nele era uma grande apatia e isso identifiquei logo no início daquele ano (1986). Como professor de Matemática, eu sempre me preocupei com os alunos que não tinham um bom rendimento. No entanto, as tentativas de incentivo, nos momentos de explicações ou resoluções de 
exercício, acompanhando de perto e retirando dúvidas, não davam certo. Na primeira avaliação o resultado foi desastroso.

Outras tentativas, como a de fazer dele uma espécie de representante meu, quando precisava me ausentar da sala ou desenvolver alguma atividade como verificação de exercícios nos cadernos, não deram certo! Nos intervalos, eu o chamava para dar mais explicações e me coloquei à disposição para tirar dúvidas sempre que fosse possivel. Na segunda avaliação, a nota também foi muito baixa. Mas após as férias de julho, um fato mudou as coisas.

Quando eu perguntei sobre as férias, Marcelo contou que estava tentando uma posição no time da Tuna Luso Brasileira. Eu contei a ele que também era 'tunante', o que realmente é fato, e então percebi o quanto isso o deixou satisfeito. Eu não podia perder a oportunidade e fui assistir a um treino do time amador da Tuna. O contentamento do Marcelo foi enorme e alguns dias depois ele me presenteou com uma camisa da Tuna, que eu guardei com muita satisfação. O maior presente foi a visível mudança do Marcelo em sala de aula. Ele não passou a ser o melhor aluno, mas sua participação e os resultados, nas avaliações, melhoraram significativamente.

(4) Em 1997 fui chamada para ministrar uma disciplina no interior do estado. Era men primeiro semestre como professora de nivel superior e me considerava muito inexperiente para assumir uma tarefa de tamanha responsabilidade. Eu iria assumir duas turmas: a que cursaria a disciplina pela primeira vez e outra formada por repetentes. Por conta destes alunos, que exigiram um professor diferente, eu iria juntar as duas turmas para as aulas teóricas (uma sala com aproximadamente 70 alunos).

Os repetentes foram categóricos em afirmar que não fariam o menor esforco para coloborar com as aulas. Ficaram conversando muito e me crivaram de perguntas para me testar. Para meu desespero, resolveram sentar na frente, ficando mais próximos do que eu realmente gostaria. Outros me procuraram depois para explicar aquele comportamento e ao 'remoer' suas justificativas, percebi que o que havia na verdade era uma resistência por causa da professora anterior. Assim, elaborei minha estratégia de conquista, ou seja, seduzi-los pelo conteúdo.

No outro dia, comecei a aula diferente. Pedi uma chance. Queria começar tudo de novo. Mas para isso eu precisava que eles se desarmassem, que eles dessem uma chance a mim e à disciplina. Conversei sobre as dificuldades que tive quando havia visto aquele conteúdo pela primeira vez. (no curso de graduação, coincidentemente com 'aquela' professora). Contei que apesar disso, aqueles organismos eram fascinantes para mim e que a cada dia eu descobria uma coisa nova sobre eles, contei algumas histórias curiosas sobre eles, mostrei várias imagens coloridas para que tentassem lembrar se já haviam visto algo semelhante, etc.

Nessa conversa de quase quatro horas, sem que eles percebessem trabalhei todo o conteúdo introdutório para a aula seguinte. No segundo dia, com alguns alunos mais sorridentes, fir a mesma coisa, me arriscando a ir ao quadro para fazer alguns desenhos e explicar mais detalhadamente alguns pontos da aula anterior. Nesse dia, pedi que eles lessem o texto que havia preparado para a aula posterior, sem compromisso de entender os processos nele mencionados. E assim, a cada dia me tornava mais atrevida e ia um pouco mais além.

Conforme já foi dito, reunimos esses 'causos' para subsidiar nossa discussão no âmbito da Educação em Ciências e Matemática segundo a tese do binômio afeto-cognição no desenvolvimento cognitivo. Examinamos os relatos via análise 
de conteúdo, num ir e vir de ideias e formulações, sem organizá-los caso por caso, pois entendemos que eles são interativos. Desse modo, mantivemos a perspectiva sistêmica e discursiva que defendemos e a fidelidade ao estilo redacional que escolhemos. Essa opção também nos levou a transferir o desfecho das narrativas para o final do ensaio. Doravante, passamos a analisar as histórias, articulando-as em discursos da área da Educação Científica e Matemática que consideramos passíveis de interação entre elas.

\section{PARA INÍCIO DE CONVERSA...}

O primeiro aspecto das narrativas que queremos analisar é o de que resistências em termos de aprendizagem se relacionam ao tipo de vínculos afetivos estabelecidos entre professores e alunos. Autores como Pietrocola e Pinheiro (2000) nos ajudam a sustentar esse pensamento porque inferem que as relações afetivas partilhadas em sala de aula possuem enorme poder no processo de significação conceitual. Outrossim, seria possível otimizar a aprendizagem dos conceitos científicos e matemáticos por meio de aspectos afetivos manifestados pelos alunos, partindo-se do pressuposto de que o professor deve ser uma referência afetiva para o estudante, uma figura que entende as dificuldades e necessidades do aprendiz.

Desse ponto de vista, em (1), (2) e (3) notamos que os docentes demonstraram ter consciência de seu papel de referência para os alunos, pois estavam dispostos a se aproximar dos estudantes para enfatizar a importância do conteúdo a ser apreendido. Fragmentos como eu estava disposto a discutir a questão com a turma, porque acho que é minha função como educador (1), eu sempre me incomodei com tais comentários (...) decidi então conbecê-la melhor (2) e eu sempre me preocupei com os alunos que não tinham um bom rendimento (3) revelam o cuidado desses professores em conhecer não apenas o que os alunos não sabiam em relação às suas disciplinas, mas também vivências e expectativas referentes à escola.

Além disso, os docentes relataram que Marcelo (3), Kevin (1) e, implicitamente, Rebeca (2) reduziram suas resistências cognitivas a partir da relação de confiança estabelecida em sala, especialmente depois de estímulos que receberam para superar suas dificuldades de aprendizagem. Em nosso entender, os indícios ele tinha um comportamento exemplar em sala, além de se mostrar disposto a superar suas dificuldades na matéria (1), o maior presente foi a visivel mudança do Marcelo em sala de aula (3) e aos poucos eu consegui pequenos avanços (2) evidenciam mudanças de comportamento daqueles alunos e avanços em sua aprendizagem, conforme a receptividade criada na interação com os professores para a assimilação dos conhecimentos científicos ou matemáticos.

Essa é uma evidência que novamente articulamos com o discurso de Pietrocola e Pinheiro (2000): "conhecimentos áridos, isto é, ensinados de forma a gerar poucos vínculos com os indivíduos, [podem ser] compensados por professores com os quais foram estabelecidas boas relações afetivas”. Os casos (1) e (2), por exemplo, relatam o isolamento, o sentimento de rejeição, os comentários negativos 
(em 1: Eles não falam comigo porque repeti de ano, professor, em 2: ela se sentia inferior às outras pessoas), e em (3) a apatia, a falta de interesse, o incômodo pela repetência (não demonstrava interesse; parecendo se sentir muito desconfortável com a situação; o que eu percebia nele era uma grande apatia), como aspectos afetivos que parecem ter influenciado a cognição dos alunos até o momento da experiência com aqueles professores. Acentuamos, portanto, que o docente de Ciências e Matemática deve estar atento às possíveis relações entre determinada demanda afetiva de um aluno e suas dificuldades de aprendizagem. Recomendação semelhante é feita por Paula e Cunha (2001) e Almeida et al. (2009), quando assinalam que o docente que se preocupa em ter um bom relacionamento com os alunos, conhecer os sentimentos dos estudantes e, principalmente, refletir sobre a importância das emoções no processo pedagógico aperfeiçoa e enriquece seu próprio trabalho.

Por outro lado, a análise das narrativas também nos permite defender o pressuposto de Dantas (1992) de que qualquer experiência cognitiva se torna significativa quando os aspectos motivacionais subjacentes são trabalhados pedagogicamente. Segundo o prisma sócio-cultural ou sócio-histórico, o pensamento nasce na esfera das motivações do sujeito, o que inclui suas emoções, interesses, impulsos, necessidades, inclinações e outras expressões de afetividade experimentadas nas interações intersubjetivas e em determinado contexto.

Dessa forma, examinando a história de Marcelo (3), notamos que surgiu um elemento motivador externo ao ambiente escolar, sem o qual as estratégias pedagógicas do professor, atestadas nos fragmentos tentativas de incentivo, fazer dele uma espécie de representante meu, não surtiram efeito. Segundo o professor relator do caso, o clube para o qual torciam foi o elemento motivador do rendimento escolar daquele aluno. Termos como eu contei a ele que também era 'tunante' e então percebi o quanto isso o deixou satisfeito mostram que o alcance do domínio afetivo, em esferas que extrapolam a escola, pode influenciar a aprendizagem do sujeito.

O relato (3) e, em maior medida, o de Kevin (1), nos levam a compreender que motivar ou promover interesse significa criar uma necessidade de aprendizagem. Este processo é deliberadamente 'provocado' e não acontece apenas em termos intelectuais, mas, sobretudo, na esfera valorativa, ideológica e afetiva (LEITE; TASSONI, 2002). Queremos dizer que gosto, interesse ou curiosidade pelas Ciências e Matemática é um aspecto afetivo construído com o auxílio do professor. Assim, Santos, F. (2007) ressalva que as características do primeiro encontro entre professor e alunos, e o reforço de determinados padrões interativos definem, em parte, as necessidades de aprendizagem. Todavia, os mecanismos que atuam nessa dinâmica não obedecem a leis de causa e efeito, segundo o que depreendemos das narrativas, visto que embora sentimentos direcionem atitudes e disposição para o aprendizado, esse processo pode acontecer tanto na forma de encanto quanto na de aversão.

O caso de Rebeca (2), por exemplo, revela que, quando o percurso educativo não leva em conta a relação dinâmica e complementar entre emoção e razão em sua forma positiva, o resultado é a falta de desenvolvimento cognitivo e, ao 
mesmo tempo, afetivo, do aprendiz. Não obstante, o professor contribui para que essa deficiência se constitua e permaneça. No caso em questão, os outros professores de Rebeca fundamentaram a crença na incapacidade intelectiva da aluna por conta de seu comportamento - 'ela não tem jeito', 'tem que ser expulsa', 'é uma marginal'. Assim, a aluna demonstrou não ter confiança em si mesma - se sentia inferior às outras pessoas e mas queria estudar e ser alguém na vida -, aspecto que foi percebido pela docente de Biologia e que, ao ser trabalhado na interação, resultou em melhoria de aprendizagem da aluna - aos poucos [a professora conseguiu] pequenos avanços.

Segundo essas evidências, entendemos que inteligência também depende de conquistas efetuadas no plano da afetividade. Pautamos essa proposição no discurso de Dantas (1992, p.90), para o qual "a afetividade depende, para evoluir, de conquistas realizadas no plano da inteligência, e vice-versa", e na consideração de Rodrigues e Garms (2007, p.35), ao acentuar que "as necessidades afetivas vão se tornando cognitivas, sendo possível considerar uma unicidade psicobiológica, na qual os aspectos afetivos e cognitivos se alternam em termos de predominância".

Com efeito, o caso de Rebeca explicita que o professor também precisa acreditar na capacidade cognitiva dos alunos mediante indícios afetivos negativos. Acerca desse argumento, Cerqueira (2006) afirma que a escola é o espaço propício para a formação integral do indivíduo e que o reforço feito em relação a determinado caractere influencia não apenas a cognição, mas a construção da personalidade do sujeito. Ignorar esse aspecto é, pois, deixar o aluno a mercê do meio, algo patente no caso 2 - ela sofreu abuso sexual aos 4 anos (...), sua mãe a abandonou, passou a ser criada pela avó, depois a avó morreu, teve que mudar várias vezes de casa (...) e aos 16 anos ganhava a vida fazendo programas.

Igualmente, a história (4) revela que muitas vezes as interações em sala de aula acontecem numa perspectiva de reforço negativo. Para Monteiro e Gaspar (2007), tal característica cria nos sujeitos sentimentos que desfavorecem o clima positivo da relação pedagógica e interferem no envolvimento com o ato de conhecer. De fato, segundo a professora de graduação, os alunos não fariam o menor esforco para coloborar com as aulas, e isso se deu porque havia uma resistência por causa da professora anterior, possivelmente pelo clima negativo criado com tal experiência. Para Santos, F. (2007), determinadas condições internas, produzidas por processos de interação com o meio, causam nos sujeitos reações emocionais denominadas sentimentos de fundo, que "contribuem ou funcionam como um obstáculo para a adoção de atitudes e posicionamentos" em sala de aula, exigindo do professor permanente reavaliação de suas estratégias.

Entendemos que os sentimentos de fundo possuem papel importante na significação em sala de aula. Temos clareza de que estes balizaram o comportamento dos graduandos em (4) (por exemplo, em ficaram conversando muito e me crivaram de perguntas para me testar; resolveram sentar na frente, ficando mais próximos do que eu realmente gostaria), originando um estado de desequilíbrio no binômio afetocognição daquele contexto. Para dar corpo à hipótese, trazemos o discurso de 
Morin (2005, p.22): "há estreita relação entre inteligência e afetividade: a faculdade de raciocinar pode ser diminuída, ou mesmo destruída, pelo déficit de emoção". Concordamos com esse ponto de vista por entendermos que a afetividade não foi explorada na vivência anterior dos graduandos (percebi que o que havia na verdade era uma resistência por causa da professora anterior), aspecto que a 'atual' professora teve que lidar como um desafio de sua prática (eu precisava que eles se desarmassem, que eles dessem uma chance a mim e à disciplina) e elaborar uma estratégia de conquista com aqueles alunos (conversei sobre as dificuldades que tive quando havia visto aquele conteúdo pela primeira vez; contei que, apesar disso, aqueles organismos eram fascinantes para mim).

Finalmente, tecemos considerações sobre os sentimentos manifestados pelos professores nos relatos. Monteiro e Gaspar (2007, p.83) afirmam que "as interações sociais em sala de aula se estabelecem e se sustentam por meio de emoções positivas propiciadas pelo professor durante todo o seu trabalho didático em sala de aula". Em (1) o professor decidiu conversar com a turma a respeito da discriminação entre não-repetentes e repetentes - não acredito que vocês não falam com 'fulano' ou 'cicrano' só porque ele é repetente; se eu tivesse um colega repetente, eu faria amizade com ele - e em (4), por sua vez, a docente dialogou com os graduandos acerca das dificuldades do primeiro dia de aula - pedi uma chance; mas para isso en precisava que eles se desarmassem. Nesses episódios, os docentes assumiram uma conduta pedagógica sob a perspectiva da influência da afetividade no processo de ensino e de aprendizagem.

Foi assim que o momento inicial de tensão em (4) transformou-se em espaço democrático no qual as diferentes noções acerca do conteúdo conceitual serviram de ponto de partida para a construção de modelos científicos da disciplina ensinada. As emoções da docente - para meu desespero, resolveram sentar na frente, ficando mais próximos do que eu realmente gostaria ou aqueles organismos eram fascinantes para mim - foram importantes para a evolução do processo educativo, especialmente por terem indicado a necessidade de rever sua prática pedagógica. Por sua vez, a conversa do professor em (1) resultou na mudança de comportamento da turma em relação a Kevin - isso fez com que alguns colegas de turma fossem se aproximando dele.

Assinalamos que os sentimentos dos professores também servem de apoio para o ensino, influenciando o modo como a mediação é feita em sala de aula. Esta formulação vai ao encontro do discurso de Almeida et al. (2009), ao apontarem que professores que sentem prazer em ser docentes utilizam os aspectos afetivos para planejar suas aulas, mudar suas estratégias de ensino e se preocupar com a aprendizagem para além da escola. Desse ângulo, entendemos que ter consciência dos próprios sentimentos ajuda o professor a perceber, refletir sobre e melhorar seu papel como educador. Os fragmentos em (1), eu estava disposto a discutir a questão com a turma, porque acho que é minha função como educador, em (3), eu sempre me preocupei com os alunos que não tinham um bom rendimento e em (4), a cada dia me tornava mais atrevida e ia um pouco mais além, corroboram nossa análise. 


\section{NÃO HAVERÁ BORBOLETAS SE A VIDA NÃO PASSAR POR NECESSÁRIAS METAMORFOSES}

Até aqui analisamos os relatos explicitando discursos que defendem a afetividade como dimensão indissociável do processo cognitivo. Nós admitimos que os aspectos afetivos trazem implicações para o ato de conhecer, a escola e seus constituintes. Sem querer esgotar o debate, nesta seção buscamos formular princípios de racionalidade para a Educação Científica e Matemática, destacando-os em negrito e enumerando-os em sequência ordinal. Ao fim, apresentamos o desfecho dos relatos.

Pelo que expusemos, as experiências cognitivas de fato acontecem no 'espaço' entre razão e emoção. Contribuições epistemológicas como as de Wallon $(1975,1995)$ e Vygotsky (1989) nos parecem profícuas para formularmos talvez aquele que seja o princípio básico de racionalidade do qual os demais derivarão: o de que nem a afetividade nem a inteligência se desenvolvem uma à margem da outra, mas conjuntamente, numa relação de filiação (princípio 1).

Defendemos uma Educação Científica e Matemática que transcenda a fragmentação do paradigma cartesiano em favor da complexidade, que inclua a afetividade, a espiritualidade, a moralidade, valores tão válidos e coerentes com as especificidades humanas quanto a razão 'pura'. Em seu turno, Santos B. (1997, 2003a, 2003b) propõe um novo paradigma para a ciência pós-moderna e o debate epistemológico que empreende nos leva a crer na necessidade de articular saberes no espaço educacional, sem privilégios para os científicos e matemáticos, incluindo-se a afetividade, a criatividade e a sensibilidade (princípio 2).

Precisamos de uma Educação Científica e Matemática que articule emoção e razão sem ser negligente com uma ou outra, visto que ensinar e avaliar somente conhecimentos intelectuais, tais como os conteúdos científicos e matemáticos, implica num desenvolvimento parcial do sujeito que aprende (princípio 3). Concordamos com Vitkowski (2004) ao assinalar que a proposta fragmentária que ainda vigora nas instituições de ensino não atende à natureza do desenvolvimento cognitivo humano. Isso tem gerado resultados incipientes em termos de uma educação integral. É preciso superar a ilusão de que o desenvolvimento da razão deve ser prioridade dos modelos educativos, mas entendemos que essa tarefa é um enorme desafio para os responsáveis pela educação. Ainda assim, é fundamental que ela seja assumida como uma inquietação permanente nas práticas pedagógicas.

Nos relatos, vimos que os processos pedagógicos são como teias de fenômenos acontecendo e influenciando diversos âmbitos. Como afirmam Seniciato e Cavassan (2008), a afetividade não é escolho para o desenvolvimento da razão e vice-versa. A racionalidade que queremos não pode se pautar apenas em aspectos racionais, por via e privilégio de deduções lógicas de raciocínio. A porta de entrada utilizada pelos estudantes para se relacionarem com o conhecimento, em especial o científico e o matemático, é também afetiva, ocorrendo na manifestação aspectos emocionais, tais como interesse, repugnância, curiosidade, motivação, etc (princípio 4).

Autores como Maturana (2001) defendem que nas experiências cognitivas 
o sujeito explica por meio das emoções. No caso do cientista, o conhecimento é construído pela paixão de explicar. Entendemos que as formas científicas e matemáticas de explicar são formas particulares de se conviver com as emoções (princípio 5). Partilhamos da ideia de Uller (2006) de que muitas vezes os professores de Ciências e de Matemática não dialogam com os alunos no sentido de evidenciar que as emoções não estão dissociadas da ação cognitiva, pois apenas não compõem os critérios de validação das afirmações científicas/matemáticas. Na verdade, postulamos que os sentimentos guiam a construção conceitual, delineando epistemologicamente o caminho do conhecer e o modo de significação.

Sobre o tema, Pietrocola e Pinheiro (2000) afirmam que o fato de os estudantes esquecerem boa parte do conhecimento aprendido nas aulas está associado não apenas a questões de ordem epistemológica e pedagógica, mas à falta de vínculos afetivos para com esse conhecimento. Assim sendo, o patrimônio afetivo dos alunos está relacionado às suas concepções prévias e resistências à adoção das concepções ensinadas em sala de aula (princípio 6). Nessa perspectiva, não há como os professores de Ciências e Matemática esperarem a assimilação de ideias no domínio lógico ou racional sem saberem de que forma as concepções alternativas dos alunos se mantém persistentes e resistentes ao novo conhecimento.

O 'teor de profundidade' das ideias prévias pode ser conhecido nas reações emocionais dos alunos. Quando um estudante diz 'não gosto de estudar cálculo estequiométrico’, podemos afirmar que ele aprendeu a não sentir prazer nesse tema em alguma experiência anterior. Para nós, fazer com que o estudante assimile uma noção científica ou matemática significa torná-la interessante do ponto de vista afetivo. Assim, defendemos a ideia de fazer com que o conhecimento ensinado seja afetivamente valorizado pelo aluno (princípio 7), visto que persistir num ensino desagradável implica reforçar negativamente essa experiência afetivo-cognitiva.

Os relatos que analisamos mostraram que, se o aluno não consegue aprender Matemática, por exemplo, não o faz simplesmente por ser 'bagunceiro'. É possível que ele tenha se tornado assim por não ter conseguido aprender Matemática, ou seja, uma demanda cognitiva não afetivamente valorizada pode ter modificado o nível de interesse e motivação do sujeito. Esta é uma perspectiva que, para Custódio (2007), amplia o espectro de avaliação do professor, porque considera a trajetória histórica do aluno ao longo dos anos escolares.

Outra questão que depreendemos dos relatos é a que a atividade educativa supera o ato de ensinar conhecimentos formais. Ela é, no entender de Kenski (2002, p.102), "um conjunto complexo, em que se misturam raciocínios lógicos, sentimentos, emoções e, sobretudo, valores... que permanecem agregados às informações apreendidas". Compreendemos que a função docente se amplia, passando a incluir a compreensão da dimensão afetiva no relacionamento aluno-aluno e/ou professor-aluno e suas influências na formação de conceitos em sala de aula.

Por sua vez, Amatuzzi (2008, p.50) assinala que usar a afetividade na escola exige dos professores uma percepção do que acontece "num plano que transcende 
o do puro cognitivo”. É a escuta sensível, prática defendida por Barbier (1998) que se apoia na empatia entre os sujeitos. Ela significa, nas palavras de Cerqueira (2006, p.32), "a disponibilidade permanente por parte do sujeito que escuta para a abertura à fala do outro, ao gesto do outro, às diferenças do outro", uma habilidade que deve integrar as discussões na formação de professores de Ciências e de Matemática. Assim, perceber os estudantes como seres intelectuais e afetivos implica em nova atitude pedagógica que precisa ser tema de debate na formação inicial e continuada de professores (princípio 8). Temáticas como 'para quê', 'para quem' e 'como' ensinar Ciências/Matemática deveriam ser discutidas também sob o ponto de vista da afetividade nos cursos de licenciatura.

Arantes (2003) propõe que nas escolas se façam estudos sistematizados dos sentimentos na forma de projetos que integrem, de modo transversal e interdisciplinar, os conteúdos tradicionalmente ensinados, tais como as Ciências e a Matemática. Para a autora, esse tipo de projeto poderia ser implementado em situações didáticas cujo tema seriam os conflitos humanos e sua resolução. Tratase, assim, de abordar os conflitos numa perspectiva ética, fazendo da escola um ambiente democrático, no qual diversos pontos de vista possam ser coordenados sem reduzi-los a modelos de autoridade (princípio 9). Esse princípio está em sintonia com as novas tendências para a Educação Científica e Matemática, sobretudo nos moldes da formação para a cidadania, para a tomada de decisão e para a prática social responsável, que usualmente utilizam como opção metodológica o trabalho com temas controversos.

Defendemos que a Educação em Ciências e em Matemática precisa ser diversificada, sobretudo porque não há alunos idênticos ou igualmente disponíveis cognitiva e afetivamente (princípio 10). É da diversidade que emerge a unidade, segundo o pensamento da complexidade, mas que não anula das partes a qualidade (MORIN, 2005). Muitas vezes os professores de Ciências e de Matemática valorizam os estudantes que rendem nas aulas, que operam satisfatoriamente com números e cálculos, que se interessam pelas disciplinas científicas, deixando de atender aos demais alunos que ainda não alcançaram esse status. É a permanência na zona de conforto que leva o docente a não incentivar os educandos que precisam de maior atenção. Desse modo, os que compõem o alunado deveriam ser reconhecidos como seres únicos e diferentes e assim, no nosso entender, se sentiriam valorizados.

Por fim, Amatuzzi (2008) entende que em nossa época reivindica-se a originalidade do ser humano, visto que ao contrário do que se aceitou com a objetividade do paradigma das ciências modernas, o que é próprio do homem é captado pelos métodos da ciência. Assim, ao invés da objetividade sujeito-objeto e outros dualismos, defendemos para a Educação Científica e Matemática a construção da objetividade das subjetividades, nascida do entendimento entre sujeitos e da compreensão do papel do outro no modo de ser e aprender (princípio 11).

Os princípios de racionalidade que evidenciamos neste texto caracterizam uma Educação Científica e Matemática que pensa na diversidade da capacidade pes- 
soal e na variedade de tempos de aprendizagem. Os relatos mostraram que as emoções não são apenas reações orgânicas determinadas mediante processos biológicos, mas também construções sócio-culturais. Assim como uma resposta emocional positiva leva a um novo 'processamento' de informações e conhecimentos, modelos culturais ou exemplos de comportamento também reforçam condutas, o que nos leva a crer que naturalmente ensinamos e aprendemos com nossa afetividade.

Ressaltamos que a tarefa de todo educador, não apenas em Ciências e Matemática, inclui conhecer melhor seus alunos, não para torná-los 'meros amigos', mas para constituir sua própria natureza histórica. No nosso entender, é ingênua a ideia de que a qualidade do ensino deriva da severidade, frieza e distância do professor. Nesse sentido, deixaremos que os desfechos dos casos falem por nós, pois eles mostram que resultados profícuos devido à 'disponibilidade afetiva' dos professores podem marcar de forma indelével a vida dos envolvidos.

(1) Infelizmente Kevin saiu da escola pouco antes do fim do periodo letivo e eu nem soube o motivo... Um dia o encontrei no periodo noturno, dizendo que alguns problemas de família o afastaram da escola. Ele gostou de saber que poderia ser meu aluno, porque me considerava um grande amigo. Eu também.

(2) Fui professora de Rebeca nos dois anos em que estive naquela escola. Sai de lá para fazer Mestrado em Educação. Quando conclui, recebi um convite para trabalhar em uma universidade particular da capital. Quando entro pela primeira vez, em uma turma de licenciatura em Biologia de tal instituição, advinha quem eu encontro, caloura de Biologia? A Rebeca! Não sei como explicar a minha felicidade! Ela não mais fazia programas, trabalhava e disse que eu marquei a vida dela. Hoje ela é professora de Biologia, concursada, tem uma filhinha e sempre nos falamos.

(3) Eu e Marcelo passamos a ser mais amigos e sempre conversávamos sobre futebol. Eu cobrava dele bons resultados nas outras disciplinas e isso aconteceu. Ele ficou de recuperação, precisando de notas altas e conseguiu passar de ano, mas acabou saindo do colégio para fazer supletivo. E nunca mais nos vimos.

(4) Na metade do curso, eis que no meio da aula, uma aluna, que eu considerava a mais 'resistente' - até aquele momento era a única que não havia mudado a opinião inicial - fez. a seguinte afirmação: 'é professora, sabe que agora estou começando a gostar da senhora?'. Fiquei parada com o giz na mão, olhando para a turma, que tinha caido na gargalhada. Refeita do susto, falei para ela: 'Fico muito feliz que você esteja começando a gostar de mim e consequentemente da disciplina'. Ela levantou, me deu um abraço e agradeceu bem baixinho no meu ouvido pela paciência com ela e com todos os resistentes e por não ter desistido deles.

Terminamos o ensaio propondo algumas questões para reflexão, enquanto professores de Ciências e de Matemática: quais têm sido nossos 'modelos de afetividade'? O que tem sustentado nosso discurso e conduta em sala de aula no sentido de incluir a afetividade como aliada do processo cognitivo? Que aspectos a pesquisa em Educação em Ciências e Matemática ainda precisa compreender para construir uma educação comprometida com o ser humano em sua totalidade? 


\section{NOTAS}

${ }^{1}$ Particularmente trata-se do debate ocorrido na componente curricular "Bases Epistemológicas da Pesquisa em Educação em Ciências e Matemática", na ocasião da apresentação oral desta pesquisa, ofertada no programa de doutorado do qual fazemos parte.

${ }^{2} \mathrm{Na}$ literatura, a conceituação de termos ligados aos fenômenos afetivos, tais como emoções, sentimentos, afetos e paixões, é diversa. Neste texto, preferimos não fazer distinção entre eles por entendermos que não acrescentaria aspectos relevantes à discussão

\section{REFERÊNCIAS BIBLIOGRÁFICAS}

ALMEIDA, L. R. et al. Afetividade e aprendizagem: o que dizem algumas pesquisas. In: CONGRESSO NACIONAL DE PSICOLOGIA ESCOLAR E EDUCACIONAL, 9., 2009, São Paulo. Anais... São Paulo: ABRAPEE, 2009.

AMATUZZI, M. M. Investigação do humano. In: AMATUZZI, M. M. Por uma Psicologia Humana. 2. ed. São Paulo: Alínea, 2008, p.45-51.

ANDRADE, P. E.; PRADO, P. S. T. Psicologia e Neurociência cognitivas: alguns avanços recentes e implicações para a educação. Revista Interação em Psicologia, v.7, n.2, p.73-80, dez, 2003.

ARANTES, V. A. Afetividade e Cognição: rompendo a dicotomia na educação. Videtur, n.23, 2003. Disponível em <http://www.hottopos.com/videtur23/valeria.htm>. Acesso em: 2 abr. 2010.

BARBIER, R. A escuta sensivel na abordagem transversal. São Carlos: UFSCar, 1998.

BARDIN, L. Análise de conteúdo. Lisboa: Edições 70, 2010.

CAGNIN, S. Algumas contribuições das neurociências para o estudo da relação entre o afeto e a cognição. Estudos e Pesquisas em Psicologia, v.8, n.2, p. 473-504, ago, 2008.

CERQUEIRA, T. C. S. O professor em sala de aula: reflexão sobre estilos de aprendizagem e a escuta sensível. Revista de Psicologia da Vetor Editora, v.7, n.1, p.29-38, jun, 2006.

CUSTÓDIO, J. F. Explicando Explicações na Educação Científica: Domínio Cognitivo, Status Afetivo e Sentimento de Entendimento. 2007. 236f. Tese (Doutorado em Educação Científica e Tecnológica) - Centro de Ciências da Educação, Universidade Federal de Santa Catarina. Florianópolis, 2007. DAMÁSIO, A. R. O mistério da consciência: do corpo e das emoções ao conhecimento de si. São Paulo: Companhia das Letras, 2000.

DANTAS, H. A afetividade e a Construção do Sujeito na Psicogenética de Wallon. In:

LA TAILLE, Y.; OLIVEIRA, M. K.; DANTAS, H. Piaget, Vygotsky, Wallon: teorias psicogenéticas em discussão. São Paulo: Summus, 1992, p.85-100.

DE PAULA, A. L. B.; CUNHA, A. M. O. As relações afetivas na sala de aula como fatores motivacionais para a aprendizagem dos conteúdos de Biologia. In: ENCONTRO NACIONAL DE PESQUISA EM EDUCAÇÃO EM CIÊNCIAS, 3., 2001, Atibaia. Anais... Atibaia: ABRAPEC, 2001.

KENSKI, V. M. O Papel do Professor na Sociedade Digital. In: CASTRO, A. D.; CARVALHO, A. M. P. (orgs.) Ensinar \& Ensinar: Didática para a Escola Fundamental e Média. São Paulo: Thomson Learning, 2002, p.95-106.

LEITE, S. A.; TASSONI, E. C. M. A afetividade em sala de aula: as condições de ensino e a mediação do professor. In: AZZI, R. G.; SADALLA, A. M. F. A. (orgs) Psicologia e formação docente: desafios e conversas. São Paulo: Casa do Psicólogo, 2002.

MATURANA, H. Cognição, ciência e vida cotidiana. Belo Horizonte: Ed. UFMG, 2001.

MONTEIRO, I. C. C.; GASPAR, A. Um estudo sobre as emoções no contexto das interações sociais em sala de aula. Investigações em Ensino de Ciências, v.12, n.1, p.71-84, mar, 2007.

MORIN, E. Os sete saberes necessários à Educação do Futuro. São Paulo: Cortez, 2005.

NEUBERN, M. S. As emoções como caminho para uma Epistemologia Complexa da Psicologia. 
Psicologia: Teoria e Pesquisa, v.16, n.2, p.153-164, ago, 2000.

OLIVEIRA, M. K. O Problema da Afetividade em Vygotsky. In: LA TAILLE, Y.; OLIVEIRA, M. K.; DANTAS, H. Piaget, Vygotsky, Wallon: teorias psicogenéticas em discussão. São Paulo: Summus, 1992, p.75-84. PEDRO, A. Discussões éticas, neurociências, emoção e razão. Interacções, n.5, p.4-13, 2007.

PIETROCOLA, M.; PINHEIRO, T. F. Modelos e afetividade. In: ENCONTRO DE PESQUISA EM ENSINO DE FÍSICA, 8., 2000, Florianópolis. Anais... Florianópolis: SBF, 2000.

RODRIGUES, A. M. M. Por uma filosofia da tecnologia. In: GRISPUN, M. P. S. (org.) Educasão tecnológica: desafios e perspectivas. 2.ed. São Paulo: Cortez, 2001, p.75-129.

RODRIGUES, S. A.; GARMS, G. M. Z. Relação professor-aluno e afetividade: reflexões wallonianas sobre o ambiente de aprendizagem e a prática docente. Série Estudos - Periódico do Mestrado em Educação da UCDB, n.23, p.31-41, jun, 2007.

SANTANA, S. M.; ROAZZI, A.; DIAS, M. G. B. B. Paradigmas do desenvolvimento cognitivo: uma breve retrospectiva. Estudos de Psicologia, v.11, n.1, p.71-78, abr, 2006.

SANTOS, B. S. Pela mão de Alice: o social e o político na pós-modernidade. 3.ed. São Paulo: Cortez, 1997. SANTOS, B. S. Introdução a uma ciência pós-moderna. 4.ed. São Paulo: Cortez, 2003a.

SANTOS, B. S. Um discurso sobre as ciências. São Paulo: Cortez, 2003b.

SANTOS, F. M. T. As emoções nas interações e a aprendizagem significativa. Ensaio - Pesquisa em Educação em Cièncias, v.9, n.2, p.151-161, 2007.

SENICIATO, T.; CAVASSAN, O. Afetividade, motivação e construção de conhecimento científico nas aulas desenvolvidas em ambientes naturais. Ciências \& Cognição, v.13, n.3, p.120-136, nov, 2008. ULLER, W. Afetividade e cognição no Ensino Médio: a desconstrução do racionalismo pedagógico. 2006. 125f. Dissertação (Mestrado em Educação) - Centro de Ciências Humanas, Letras e Artes, Universidade Estadual de Ponta Grossa. Ponta Grossa, 2006.

VITKOWSKI, J. R. Epistemologia e educação: conhecimento para uma vida decente. Analecta, v.5, n.1, p.9-22, jun, 2004.

VYGOTSKY, L. S. Pensamento e linguagem. 2.ed. São Paulo: Martins Fontes, 1989.

WALLON, H. Psicologia e educação da infância. Lisboa: Editorial Estampa, 1975.

WALLON, H. A evolução psicológica da criança. Lisboa: Edições 70, 1995.

Data de Recebimento: 21/11/2010

Data de Aprovação: 15/062011

Data da Versão Final: 25/05/2011 